\title{
CAPÍTULO XVI
}

\section{Desafíos para la construcción de una agenda ambiental en el regionalismo. El caso de la Alianza del Pacífico}

\author{
María Eugenia Vega* \\ Hadrien Lafosse ${ }^{* *}$
}

* Politóloga Universidad de Buenos Aires. MSc en Defensa Nacional, Escuela de Defensa de la República Argentina. Doctoranda en Ciencias Sociales Universidad de Buenos Aires. Docente de la Universidad de Buenos Aires, profesora visitante e investigadora en la Maestría en Ciencia Política de la Universidad de Los Andes, Mérida, Venezuela. Actualmente profesora investigadora Profesora investigadora de tiempo completo del Programa de Negocios Internacionales. Universitaria Agustiniana (UniAgustiniana). Bogotá DC

** Pregrado en Comercio Internacional, Lycée Marcelin Berthelot, Saint Maur, Francia. MSc en Administración de Empresas, NEOMA Business School, Reims, Francia. Profesor investigador tiempo completo del Programa de Finanzas y Comercio Internacional, Facultad de Ciencias Económicas y Sociales, Universidad de La Salle, Bogotá. Miembro del grupo de investigación Economía y Desarrollo Humano de la Universidad de La Salle, categoría B de Colciencias. Sus últimas investigaciones versan sobre aspectos que enlazan seguridad ambiental e integración regional. 


\section{Introducción}

En un contexto internacional marcado por la creciente complejidad de los fenómenos de carácter interméstico, es menester contribuir a la discusión de los problemas ambientales desde una perspectiva que considere plausible el tratamiento de sus consecuencias indeseadas. En el caso de América Latina, es por demás evidente lo crucial de la problemática con economías predominantemente agrícolas y aunque es innegable que estos aspectos afectan al planeta en su totalidad, son precisamente los habitantes de los países en desarrollo los más vulnerables a sus efectos ya que dependen -directa o indirectamentede actividades primarias para su supervivencia y bienestar (Renner, 2004).

Desde esta perspectiva, emergen como variables a considerar, la intrínseca relación entre cambio climático, biodiversidad ${ }^{1}$ y desarrollo sustentable, por cuanto el cambio climático acelera la pérdida de diversidad biológica mientras que el desarrollo sustentable puede ser considerado como un modelo social que, basándose en el respeto por el ecosistema, busca un nivel de crecimiento que se pueda sostener en el tiempo ${ }^{2}$, de manera que hoy en día es considerado como un paradigma del desarrollo que exige cambios en la conducta humana con la intensión coherente de una visión de desarrollo económico y social desde una perspectiva ecológica. Es decir, esta relación incluye -entre otras tantas- cuestiones tan álgidas para Latinoamérica como la reducción de la pobreza y la garantía de la seguridad alimentaria.

1 Debe anotarse que en esta introducción se da por sobreentendidas las nociones de cambio climático y diversidad biológica además de que se desarrollarán en profundidad desde el tratamiento de las respectivas agendas ambientales nacionales. No así con el siguiente concepto por cuanto, como se puede apreciar más abajo, se trata de un paradigma en permanente construcción.

2 En este planteo no se tomará en consideración profundizar sobre el desarrollo de este concepto, pero sí se entiende la importancia de destacar que, a pesar de las múltiples definiciones en este sentido, el mismo parte del conocido Informe Brundtland (1987), construyéndose paulatinamente a partir de The World Development Report (1991), la Declaración de Río y la Agenda 21, aspectos luego profundizados en los llamados Objetivos de Desarrollo del Milenio y en la Cumbre sobre Desarrollo Sostenible (Johannesburgo, 2002). Finalmente, se recomienda consultar los Objetivos de Desarrollo Sostenible: 17 objetivos para transformar nuestro mundo (2015), en http://www.un.org/sustainabledevelopment/es/objetivos-de-desarrollo-sostenible/ así como el Acuerdo de Paris (2015) https://unfccc.int/ resource/docs/2015/cop21/spa/I09s.pdf 
Debido a estas apreciaciones y bajo la lógica de la muldimensionalidad de los problemas ambientales, se sobreentiende, que éstos sólo pueden ser afrontados a partir de la acción concertada de y entre varios Estados. Esto no constituye ninguna novedad desde que la cuestión ambiental fue incorporada a la agenda internacional en los años 70 del siglo pasado y así, lo muestran los distintos acuerdos específicos surgidos ante la inusitada aceleración de estos procesos derivados de la globalización y el predominio del neoliberalismo.

Sobre la base de estas consideraciones es, entonces, que se plantea la necesidad de adecuación y concordancia entre las políticas nacionales y subregionales con los marcos internacionales. Situándose particularmente en América Latina, se da por entendido aquí que la estrategia más adecuada para la concertación de políticas que den paso a instituciones de alcance regional en materia ambiental es el regionalismo (Vega, 2013, p. 246). Si bien, existe una amplia discusión académica acerca de las distintas formas que asume el regionalismo latinoamericano en la actualidad, no caben dudas acerca de que los acercamientos entre los Estados se presentan cada vez más multitemáticos debido a la importancia creciente de la cooperación en temas distintos de la esfera estrictamente económica.

La presente propuesta, preliminar y sin pretensiones de exhaustividad, propende contribuir a esta discusión, estudiando particularmente el caso del acuerdo de integración regional Alianza del Pacífico (en adelante, AP), elección debida a una serie de particularidades. Por una parte, presenta características bien diferenciadas respecto de las arquitecturas de integraciones tradicionales, basadas en modelos de proximidad geográfica y de búsqueda de concertación de políticas que exceden los marcos netamente comerciales. En segundo lugar, muestra claramente la apuesta hacia la región Asia-Pacífico, poniendo de manifiesto la creciente importancia estratégica de esta zona del mundo en detrimento del Atlántico. Por último, despierta interés una iniciativa reciente que en su objetivo principal destaca profundizar en los acuerdos económicos, comerciales y de integración entre los Estados miembro sobre la base de la libre circulación de bienes, servicios, capitales y personas e "impulsar un mayor crecimiento, desarrollo económico y competitividad de las economías de sus integrantes, con miras a lograr mayor bienestar, superar la desigualdad socioeconómica e impulsar la inclusión social de sus habitantes" (https://alianzapacifico.net/que-es-la-alianza/) 
Esto, lleva a preguntarse qué plantea la Alianza en términos de la inclusión de las problemáticas relativas al medioambiente -entendidas aquí como inherentes a objetivos propuestos- y cuáles podrían ser las perspectivas a mediano plazo para la consecución de una agenda ambiental propia de la Alianza del Pacífico. Explorar las agendas ambientales de los países que componen este acuerdo, cobra especial relevancia, no sólo por la innegable repercusión del comercio internacional sobre el medio ambiente y por las especiales características de la AP que se mencionan más arriba. También, con el hecho de que los cuatro miembros no son contiguos, debe destacarse e incluirse lo relativo al medioambiente en el Océano Pacífico, ya que es lo geográficamente los une. Sin embargo, debe adelantarse que sólo a través de una mirada a vuelo de pájaro se denotarán los principales problemas ambientales que aquejan a esta región del océano así como de las costas de los Estados miembro.

Además, se plantea la necesidad de indagar en las agendas nacionales ambientales donde los problemas ambientales se constituyen en tema no menor, en tanto, predomina el extractivismo como característica central de las economías en cuestión y una importante proliferación de proyectos de infraestructura que sin lugar a duda tendrán fuertes repercusiones sobre el medio ambiente pacífico.

En la primera sección se discuten los conceptos de regionalismo e integración regional en América Latina -con particular énfasis sobre en América del Sur- y sus actuales tendencias a fin de caracterizar el marco de inclusión de los problemas relativos al medio ambiente. Luego, se esboza un breve bosquejo sobre el tratamiento que ha dado recientemente la academia sobre la relación entre las temáticas que aquí ocupan. En segundo término, se examina críticamente la inclusión de lo ambiental en la AP, donde destaca la participación de sus miembros en la Conferencia de Naciones Unidas sobre Cambio Climático $\left(\mathrm{COP}^{3}\right)$ y la Declaración de los Ministros de Ambiente de la AP "Hacia una Plataforma de Crecimiento Verde (2016).

3 Tradicionalmente referidas así las Conferencias de Cambio Climático de la ONU por "Conferencia de las Partes", celebradas anualmente y derivadas de los escasos resultados de la Conferencia de Copenhague (2009), la que debía preparar los objetivos a reemplazar ante la finalización en 2012 de lo estipulado en el Protocolo de Kyoto. 
De aquí se sigue, con el análisis de las agendas nacionales ambientales de los países que integran el bloque subregional a partir del análisis de contenido. La elección de esta técnica de investigación cualitativa se debe a que parte del principio de que examinando textos es posible conocer no sólo su significado, sino también información al respecto de su modo de producción ${ }^{4}$. Destaca aquí el hecho de centrarse en todos los elementos normativos que regulan el sector en este ámbito específico, desde lo que aquí se presenta como su tratamiento en dos niveles de análisis: el primero, examina la normativa ambiental desde el nivel constitucional hacia las leyes generales y las instituciones ambientales en los Estados miembro, mientras que el énfasis está puesto sobre todo en un segundo nivel -Programas y Estrategias de Acción, ya que se considera que es donde puede mejor se puede, gracias a esta técnica, identificar si los contenidos analizados son convergentes -apuntan todos al logro de un objetivo común-, divergentes -el logro de los objetivos de un país entorpece el logro de los objetivos de otros Estados-, o compatibles -el logro de los objetivos de un Estado no entorpece los de los demás países, por lo que pueden alcanzarse sin entrar en contradicción- En quinto lugar, se ciernen una serie de conclusiones acerca de si las agendas nacionales ambientales podrían constituirse en punto de partida para una agenda ambiental propia del esquema de integración regional.

\section{Regionalismo y medio ambiente. Elementos teóricos y esbozo de un estado del arte}

Líneas más arriba se adelantaba como una premisa central guía para este trabajo que el regionalismo constituye la respuesta más idónea para la atención de los problemas relativos al medio ambiente por cuanto se trata de una cuestión multidimensional -como se señaló en la Introducción, bajo la lógica del intrínseco entrelazamiento entre cambio climático, biodiversidad y desarrollo sostenible- que afecta por igual a los Estados, y sus respectivas sociedades. El regionalismo no es algo novedoso en la subregión y mucho se ha escrito al respecto, desde mediados del siglo XX, sin contar con la fuerza que tomó a partir del proceso de globalización pero por sobre todo, des-

4 Es decir, trata los textos no sólo como signos dotados de un significado conocido por su emisor, sino como indicios que dicen sobre ese mismo emisor, o generalizando, indicios sobre el modo de producción de un texto (Krippendorf, 2004, 36). 
de el punto de vista netamente económico ${ }^{5}$. Si bien no es el objetivo fundamental profundizar teóricamente respecto de los conceptos de regionalismo e integración regional así como de sus diferencias y cambios a lo largo del tiempo, resulta importante señalar algunos criterios sin los cuales esta investigación carecería de marco.

En principio, la idea de regionalismo debe diferenciarse de integración, ya que muchas veces el uso de ambos conceptos ha carecido de rigor utilizándoselos de forma indiscriminada (Caldentey del Pozo y Santos Carrillo, 2013, p. 3) De esta manera y a fin de ilustrar, puede afirmarse que si el regionalismo refiere a "(...) la eliminación de las barreras naturales desarrolladas por los países, los procesos de integración intensifican las relaciones entre éstos, alcanzando un grado de identidad más allá de la mera formación de pactos interfronterizos" (Bergamaschine Mata Diz y Ribeiro Volpini Silva, 2001, p. 92). Marcada la necesaria diferenciación, es innegable que se trata de dos conceptos estrechamente relacionados. Durante varias décadas la integración regional ha estado fuertemente ligada a la vecindad geográfica, y adicionalmente para el caso latinoamericano estos procesos tradicionalmente han sido analizados en comparado y a veces extrapolando la fórmula europea. Definiciones tradicionales como aquella tan representativa de Haas $^{6}$ han quedado abiertamente superadas y perimidas ante esta nueva fase, la que es ampliamente tratada en la literatura actual. Mucho se ha discutido acerca de que si lo que se presencia actualmente en términos de la integración sudamericana refiere a una creciente tendencia hacia la fragmentación (Mellado, 2013).

5 Debe destacarse que las opiniones en este sentido son encontradas. Un ejemplo es discutido en el trabajo de Bergamaschine, Mata Diz y Ribeiro Volpini Silva (2011, p. 91, citando a French Davis, 2000 y Barbiero y Chalout, 2001) hace referencia al hecho de que "La regionalización económica (...) es tan antigua como la globalización y, distintamente de lo que se pueda pensar, no es una consecuencia de esta ni una respuesta estricta de los Estados nacionales a dicho movimiento".

6 Proceso por el cual los Estados nacionales "se mezclan, confunden y fusionan voluntariamente con sus vecinos, de modo tal que pierden ciertos atributos fácticos de la soberanía, a la vez que adquieren nuevas técnicas para resolver conjuntamente sus conflictos". (Haas, 1971, 6) 
Volviendo a la cuestión del regionalismo ${ }^{7}$, en los años noventa predominó la lógica del denominado regionalismo abierto ${ }^{8}$; por el contrario, la tendencia actual muestra lo que podría denominarse una nueva fase del regionalismo donde se asiste a la presencia, por ejemplo, de arreglos que proliferan de forma geográficamente dispersa, siendo tal vez uno de los exponentes más claros el caso de los BRICs ${ }^{9}$. Por su parte, el fracaso de la estrategia del Área de Libre Comercio de las Américas (ALCA) dio paso a una importante serie de acuerdos Norte-Sur, significó una mayor fragmentación intrarregional entre aquellos Estados donde predomina la visión de los incentivos para la competitividad y la eficiencia frente a aquellas posturas que denotan la naturaleza asimétrica de negociaciones que inclinan la balanza hacia los países más ricos. En este sentido, la literatura específica sitúa la discusión en torno de dos ejes: el regionalismo neoliberal y el denominado posliberal (Sanahuja, 2008, 2010, 2012) o post hegemónico (Riggirozi, 2010).

El primero se ubica sobre la base de la expansión del regionalismo abierto, con estrategias hub and spoke caracterizadas por acuerdos bilaterales de libre comercio Norte-Sur y una mayor orientación hacia los mercados externos (Reza, 2006) y siendo el imperativo una mayor flexibilidad, no profundiza en compromisos que vayan más allá de zonas de libre comercio (Sanahuja, 2012, p. 31). Así, se han "expandido entre aquellos países latinoamericanos que muestran una dependencia intensa del mercado norteamericano, con presidentes proclives a las reformas neoliberales y a su anclaje respaldados también por intereses económicos que apoyan este tipo de acuerdos" (Quiliconi, 2014, 167). Sin dudas, es una de las cuestiones que mayores divisiones ha generado a nivel sudamericano, siendo su mayor víctima la Comuni-

7 Omitiendo el "viejo regionalismo", concepto utilizado durante la Guerra Fría que hacía referencia tanto a las estrategias de integración económica con diferentes niveles de autonomía para llevar adelante políticas de desarrollo como a las organizaciones regionales de seguridad lideradas por Estados Unidos. (Sanahuja, 2012, p. 10).

8 Propuesta de la CEPAL (1994) que fomentó principalmente la apertura comercial en la región sudamericana dada la cercanía geográfica y la necesidad regional de competir desde una posición más robusta en los mercados internacionales. el estrechamiento de las relaciones comerciales sobre cualquier otro tipo de alianza regional.

9 Acrónimo que hace referencia a la asociación económica comercial de las economías emergentes más importantes del mundo como China, Rusia, Brasil e India -incorporándose posteriormente Sudáfrica- acuñado por Sachs (2001) sobre la base de su previsión de que éstas serán predominantes hacia la década de 2050. 
dad Andina de Naciones (CAN) ${ }^{10}$ Respecto del segundo destacan los casos de la Alianza Bolivariana para los Pueblos de Nuestra América (ALBA-TCP) y la Unión de Naciones Sudamericanas (UNASUR), donde a grandes rasgos destacan un "retorno a la política" en detrimento de la agenda comercial y la liberalización económica, con un fuerte discurso nacional, énfasis en el rol del Estado y las políticas ligadas al desarrollo social así como una fuerte impronta anti estadounidense. De forma que "esto ha dado una apariencia de agenda renovada en temas como la paz, la seguridad, la defensa, la gestión de crisis y la coordinación de política exterior" (Sanahuja, 2012, p. 32).

Posiciones intermedias como la CEPAL (2012) prefieren referirse acerca del interrogante sobre proyectos competitivos o complementarios y más específicamente, de "convergencia en la diversidad" o de "regionalismo a la carta", en términos de Quiliconi (2015). Lo que resulta indudable es el enorme rompecabezas que presenta el entorno latinoamericano y que entre los nuevos desafíos del regionalismo no deben perderse de vista las estrategias que los distintos gobiernos pueden generar para converger o fragmentar, dependiendo de cuál sea la postura (Zapata, 2004). Todo esto va de la mano con la creciente importancia estratégica que asume la región Asia-Pacífico en detrimento del Atlántico. Si bien aquí no se entrará en la discusión que académicamente se está planteando como una suerte de "¿Atlántico versus Pacífico?", es importante destacar que el contexto internacional aparece con una mayor diversificación del poder económico y las repercusiones de dos tendencias económicas diferenciadas como Estados Unidos y China inciden de diferentes formas en las distintas subregiones de América Latina (Rojas Aravena, 2013, citado en Servin, Martínez y Ramazini Júnior, 2014, p. 12). Según Bitar (2013) las políticas exteriores de los Estados latinoamericanos se encuentran frente a la disyuntiva de "(...) buscar articular una combinación adecuada de iniciativas de relacionamiento con China y el área de Asía-Pacífico en general, y, a la vez, con los Estados Unidos y la Unión Europea" (p. 37). No obstante, sin dejar de lado la relevancia de la relación Sur-Sur.

10 Como caso más resaltante aunque no única consecuencia que permite esta afirmación, la salida de Venezuela de la CAN en 2006 y su solicitud de ingreso al Mercosur. 
Sin profundizar en estos aspectos, ya que no se tratan del norte de esta discusión preliminar, lo que sí importa es resaltar que los acuerdos regionales stricto sensu siempre responden a propósitos que sobrepasan la frontera meramente económica, aunque se traten de arreglos formulados para fomentar el desarrollo económico. Sin embargo, y ya haciendo énfasis en el eje que aquí ocupa, las cuestiones relativas al ambiente tratadas dentro de la perspectiva del regionalismo y la integración en la subregión no han sido abordadas de forma muy extensa. En principio, la temática ha sido tratada de manera muy general, se dispone de poca bibliografía actualizada y la mayor parte de los estudios hacen énfasis en procesos como Mercosur y CAN, si bien posteriormente -y por razones obvias- comienzan a incorporarse UNASUR y en menor medida ALBA. Puede verse que la literatura sobre el tema se centra alrededor del cambio de siglo, momento en el que las políticas propuestas por el Consenso de Washington comienzan a mostrar sus consecuencias ambientales en la región. Una fuerte crítica a este respecto es la propuesta por Gudynas (2002) ${ }^{11}$; desde un planteo diferente, destacan trabajos como el de von Moltke y Ryan $(2001)^{12}$.

La fortaleza en las investigaciones relativas a procesos como Mercosur y CAN no sólo se debe a que se tratan de arquitecturas de ya larga data, sino a su vez que, si bien no han alcanzado un alto grado de institucionalidad, han plasmado normativas y grupos de trabajo específicos en su búsqueda por regular las consecuencias que sobre el medio ambiente plantea el comercio interregional. Aquí existe una producción más amplia y actualizada ${ }^{13}$. Algo similar ocurre en el caso

11 Planteando la inviabilidad ambiental del Mercosur, propone la reconstrucción de la ciudadanía y la democratización de la integración como eje para una transformación hacia la sustentabilidad

12 El trabajo sostiene que los Principios de Winnipeg constituyen un marco útil para analizar los acuerdos desde comerciales desde el punto de vista del desarrollo sustentable, enfatizando en el caso de Mercosur.

13 Entre los análisis en detalle pueden citarse, por ejemplo, la producción de Moreira (2012a) reflexionando acerca de la dimensión ambiental de Mercosur sobre la base de sus desarrollos institucionales y normativos más relevantes y posteriormente (2012b) planteando el espacio de convergencia que significa UNASUR por las oportunidades que podría brindar un fondo de implementación de planes y proyectos ambientales junto con la propuesta de un mecanismo de financiamiento que concrete los objetivos ambientales propuestos en la Carta Constitutiva de la misma. Desde otro punto de vista De Lisio (2013) discute los retos sobre el tratamiento del desarrollo sustentable en los acuerdos sudamericanos bajo la interrogante "¿avances o retrocesos?, explorando los casos de Mercosur, CAN, UNASUR, ALBA y CELAC. 
de la CAN, pudiendo citarse más no sea sólo a modo ilustrativo el trabajo comparado de las políticas ambientales en la Unión Europa, la CAN y Mercosur de Bustamante (2011) o el análisis desde el punto de vista jurídico que provee Naranjo Morales (2013), quien bajo la perspectiva del Derecho Ambiental y el estudio de los principales instrumentos internacionales, regionales y subregionales, busca establecer un diagnóstico del tratamiento iberoamericano sobre la protección ambiental.

Como antecedente más cercano a este trabajo desde el punto de vista metodológico, cabe citar la investigación de Rodríguez Becerra y Espinoza (2002), quienes presentan como eje la gestión ambiental en América Latina. Aquí se abordan, entre otros temas, los aspectos ambientales considerados críticos, las similitudes y diferencias en los mismos entre los Estados y los marcos regulatorios nacionales a la vez que su inclusión en los tratados de integración y en las alianzas subregionales, brindando aun en la actualidad elementos valiosos para los estudiosos de estos temas. Finalmente, otros abordajes incluyen nuevas perspectivas respecto de la relación entre medio ambiente e integración regional, como los casos de Vega $(2013)^{14}$ y Stuhldreher (2013). ${ }^{15}$

Incorporando el caso que aquí ocupa, la AP, puede observarse en los últimos años toda una serie de discusiones que abarcan un amplio espectro académico e ideológico. Sin embargo, la gran mayoría de los trabajos se ubican alrededor del debate planteado más arriba y entre los más destacados y completos, Serbin (2014) dedica todo el №10 del Anuario de la Integración Regional de América Latina y el Caribe a la cuestión "¿Atlántico vs. Pacífico?: América Latina y el Caribe, los cambios regionales y los desafíos globales". En un sentido similar Ardila (2012) con El Pacífico latinoamericano y su inserción internacional, donde destaca por ejemplo la investigación de Briceño Ruiz "La Alianza del Pacífico: la viabilidad de un naciente bloque regional” (pp.

14 Trabajo centrado en las problemáticas ambientales como componentes de la seguridad, para lo que introduce el concepto de seguridad ambiental, considerado como una herramienta para la desecuritización, la cooperación y la solución pacífica de las controversias.

15 Desde el enfoque del constructivismo social como marco interpretativo para analizar el aporte de las comunidades epistémicas y de la sociedad civil, estudia los avances realizados en materia ambiental para una agenda conjunta en el Mercosur, considerando específicamente los casos de Argentina, Brasil y Uruguay. 
135-158). García (2013) va más allá acentuando la necesidad de un marco conjunto para enfrentar un problema común e inminente como lo es el narcotráfico. No obstante, la variable ambiental no es tomada en consideración en ninguno de estos casos.

Un intento por poner sobre el tapete la discusión acerca de la interrelación entre el tema comercial y el ambiental en los países que integran la Alianza del Pacífico se encuentra en el documento de la Fundación Friedrich Naumann "La ruta hacia la Alianza del Pacífico. Situación del comercio y el ambiente en los países miembro y países observadores candidatos a miembro" (2014). Se exploran los acuerdos comerciales vigentes y la legislación nacional ambiental en los países citados, pero es dable resaltar que sólo se reduce al estudio del cambio climático. Por último, en un trabajo reciente (Vega, 2015) se presenta la situación general del problema ambiental en los acuerdos de integración sudamericanos, con la salvedad de incorporar a la AP. Si bien las conclusiones arrojan los problemas que en general derivan de la ausencia de supranacionalidad en las arquitecturas regionales, respecto del caso aquí bajo estudio se critica fuertemente que aparentemente sólo existe preocupación por el cambio climático. También, se hace manifiesta la preocupación acerca de lo que se denominan como "silencios" en términos de una agenda que contemple los problemas ambientales desde su multidimensionalidad, especialmente sobre la conflictividad alrededor de las actividades mineras.

\section{La Alianza del Pacífico y el medioambiente}

Como se mencionaba más arriba, la proximidad geográfica no es precisamente la característica central de la AP, la que rompe en la región los modelos tradicionales de regionalismo. Sin embargo, sus miembros no son contiguos, pero en términos ambientales están geográficamente unidos por el Océano Pacífico. Si bien, las fuentes consultadas son muy amplias, variadas y completas, adentrarse en los problemas ambientales del Pacífico así como en lo que respecta a las singularidades de las costas de los países miembros de la AP supondría correr el riesgo de perder el rumbo del presente abordaje; el detalle sería poco sencillo de agotar y por lo mismo, no se plantea aquí más que un pequeño esbozo, tal y como fue expresado en la Introducción. 
Efectivamente, los problemas ambientales sobre esta zona específica del Pacífico comenzaron a ser puestos en consideración sobre todo a partir de la década de los 90, donde se hizo evidente el deterioro de sus costas y el medio marino, ya que los sistemas marinos y costeros de la región se encuentran entre los más productivos del mundo, contienen una amplia biodiversidad y sustentan una compleja interacción de ecosistemas (Gallopín, 1995, citado en Becerra, 2002). En el año 2000, una de las preocupaciones centrales estaba en los efectos de las pesquerías, momento en que las estimaciones señalaban que un $40 \%$ de las existencias comerciales explotables en el Pacífico Suroccidental se encontraban en máxima explotación, sobreexplotación o agotamiento (PNUMA, 2000, citado en Becerra, 2002) ${ }^{16}$. La contaminación marina proveniente de tierra ocupa un lugar destacado con la conversión del suelo para uso agrícola, urbano o turístico. Los derrames de sustancias peligrosas en accidentes de buques de carga, la extracción de combustibles fósiles, desechos industriales y nucleares, emisiones, plásticos y una innumerable lista de factores que repercuten, siempre, de manera negativa sobre los hábitats costeros, manglares, estuarios, arrecifes coralinos y el océano en general.

En el caso colombiano, preocupa que la costa pacífica es la principal puerta del comercio exterior, ya que el puerto de Buenaventura moviliza el incesante crecimiento de este, región que por lo mismo, requiere de vías adecuadas de comunicación e incremento de la infraestructura ${ }^{17}$. Lo que además destaca de esta zona es la enorme biodiversidad, pero cerrada en la encrucijada de combinarse con la más extrema pobreza, en un círculo vicioso que presiona más y más sobre el medioambiente. En Perú, la minería formal e informal, la industria pesquera con alto grado de informalidad y caracterizada por la sobrepesca, con aguas contaminadas e insalubridad por efluentes de la industria de harina de pescado, se desarrolla en un entorno

16 Con el auge de la apertura económica en América latina, países como Chile o Perú aumentaron drásticamente las toneladas métricas de su capacidad de pesca, sobreexplotación que suele estar cruzada naturales que repercuten sobre la abundancia de los recursos, como el caso de la corriente de El Niño.

17 Información amplia al respecto puede hallarse en el Informe sobre el estado de los recursos naturales y del ambiente (2015-2016), realizado por la Contraloría General de la República. Disponible en http://www.contraloria.gov.co/documents/20181/461292/Informe+sobre+el+Estado+de+los+Recursos+Naturales+y+del+Ambiente+2015+-+2016/ b89427cb-857e-407c-9ef3-1aac6aaf3708?version=1.1 
de ecosistemas marinos de enorme biodiversidad desprotegidos ${ }^{18}$. Chile presenta las particularidades del caso al ser un país volcado al Pacífico en toda su geografía, de manera que tanto las actividades en ambientes acuáticos como terrestres afectan de una $u$ otra forma al océano. Resaltan la contaminación marina, los residuos de la industria pesquera, el estrés hídrico debido a las actividades extractivas, la sobreexplotación pesquera y la marea roja. ${ }^{19}$ Es también por demás preocupante que en el 2016, Chile entró en la lista de los 10 países más afectados por el cambio climático en el mundo, tomando en cuenta que alberga el $82 \%$ de la superficie glaciar en América del Sur. (http://www.uchile.cl/noticias/128419/chile-entre-los-diez-paisesmas-afectados-por-el-cambio-climatico, 14 de noviembre de 2016) Por su parte en México, la zona del Pacífico es prácticamente de flujo turístico y hay pocos puertos, como el de Salina Cruz, en Oaxaca, el de Ensenada o Rosarito, en Baja California, que son puertos pesqueros y las áreas de presión ambiental que provienen del desarrollo turístico y de la pesca intensa. Aquí, los problemas ambientales más agudos se sitúan en el Golfo de México. Sin embargo, preocupa la extracción de minerales en aguas internacionales que colindan con el Pacífico mexicano, en el Archipiélago de Revillagigedo, ya que al menos 32 países han demostrado su interés en la extracción de estructuras polimetálicas denominadas nódulos de manganeso; cada uno estos contienen altas concentraciones de cobalto, plata, cobre, oro, cadmio y níquel. ${ }^{20}$ Los proyectos de infraestructura para desarrollar estas regiones sin dudas conllevarán un fuerte impacto ambiental, del que también sobran los silencios por parte de los Estados en cuestión.

18 De ser necesaria mayor indagación sobre este particular, se recomienda Perú: Anuario de Estadísticas Ambientales 2015, producto del Instituto Nacional de Estadística e Informática. Disponible en https://www.inei.gob.pe/media/MenuRecursivo/publicaciones_digitales/Est/Lib1342/libro.pdf

19 Un estudio detallado a pesar de su ya larga data, región por región, puede ser consultado en Aedo, M. y Larraín, S. (2005) Impactos ambientales en Chile: Desafíos para la sustentabilidad. Programa Chile Sustentable, disponible en http:// www.archivochile.com/Chile_actual/patag_sin_repre/03/chact_hidroay-3\%20 00014.pdf

20 Una visión pormenorizada y completa se condensa en el Informe de la situación del medioambiente en México. Compendio de estadísticas ambientales, indicadores clave y de desempeño ambiental (2013), confeccionado por la Secretaría de Medio Ambiente y Recursos Naturales de México. Disponible en http://apps1. semarnat.gob.mx/dgeia/informe_12/pdf/Informe_2012.pdf 
Por otra parte y dando cuenta de la acotación también adelantada en la introducción, de todas maneras es propio que quede plasmada la preocupación por el extractivismo como característica central de estas economías. Sólo una mirada a vuelo de pájaro da cuenta de que Perú fue denominado en el año 2014 como el tercer productor mundial de plata, cobre, zinc y estaño, cuarto de plomo y quinto de oro según la Sociedad Nacional de Minería, Petróleo y Energía de Perú (2015); Chile es el primer productor de cobre en el mundo, el tercero en molibdeno y el séptimo en plata; Colombia abunda en proyectos mineros tanto subterráneos como de tajo abierto para carbón y oro así como su economía se centra en el explotación del petróleo, mientras que México, también dependiente de la explotación de hidrocarburos como el petróleo, es el primer productor mundial de plata $^{21}$ La creación de la AP constituye una muestra de las distintas percepciones que existen en América Latina respecto del regionalismo y del vuelco hacia las potencialidades que se vislumbran sobre el Pacífico para las próximas décadas. Las discusiones provienen desde todos los espectros ideológicos 22 pero no se tratarán aquí esas controversias ya que para tomar posición crítica esta investigación se enmarcó en primera medida en señalar los tipos de regionalismo en América Latina

No obstante, autores como Serbín (2014) plantean que, a diferencia de los otros acuerdos presentes en la región, la AP busca una inserción más ventajosa en el sistema económico internacional enfrentándose abiertamente con la globalización a la vez que apostando "a convertirse en una plataforma de proyección política y comercial con miras al mundo, dando especial importancia a la región Asia-Pacífico". Bartesaghi (citado en Serbín, 2014) entiende que este "aspecto es central en el futuro de la AP, dado que los países que integran dicho proceso parecen leer de forma correcta los cambios

21 A fin de profundizar en las graves problemáticas por las que atraviesa el Pacífico mexicano, se recomienda consultar Botello, Páez-Osuna et al (2014) Pacífico mexicano. Contaminación e impacto ambiental: diagnóstico y tendencias. UAC, UNAM-ICMYL, CIAD MAZATLÁN, CIBNOR, CICESE, 930 p.

22 Desde la izquierda ha sido objeto de numerosas críticas por cuanto se la entiende como parte de la estrategia estadounidense por erosionar, fracturar y sabotear la búsqueda de autonomía de la región (Foro de Sao Paulo, 2013; Borón, 2013). En su momento el caso de Ecuador, quien tildó de "neoliberal" su agenda. En este sentido, en la actualidad resta aguardar qué postura asume el nuevo gobierno de este país, el que aunque proviniendo del partido de su antecesor, ya ha demostrado ciertos distanciamientos respecto del mismo. 
estructurales que se dieron en la economía, comercio y geopolítica mundial en los últimos años" (p. 34). Resalta por sobre todo que AP puede tener un

\begin{abstract}
“(...) un fuerte impacto sobre el proceso de la integración regional en América Latina en base a un enfoque diferente. La AP revaloriza el comercio y la economía, por contraposición al rechazo del ALBA a los Tratados de Libre Comercio [...] La presencia de México en la AP rompe por la vía de los hechos la disyuntiva entre América del Sur o América Latina en su conjunto" (Saltalamacchia Ziccardi, 2014, p. 427)
\end{abstract}

Es en este contexto, entonces, donde desea explorarse el tratamiento dado a las problemáticas ambientales. Si bien, ya se resaltó acerca de su reciente constitución, se da por sentado que su acento netamente comercial debe estar respaldado por la creación de normativas e instituciones ambientales acordes a los indudables impactos no deseados que sobre el medio ambiente trae aparejado el comercio internacional. Indefectiblemente se debe hablar de una regionalización de la política ambiental por la sencilla razón de que cualquier área donde el comercio exterior tenga un papel importante, deberá incorporar el impacto ambiental a sus criterios de regionalización. Por el momento esto es una deuda; desde el punto de vista operativo la AP sólo posee el llamado Comité Científico, cuyo objetivo es que instituciones y especialistas de los Estados parte vinculados a la temática relativa al medioambiente -con especial énfasis en la cuestión del cambio climático- puedan articular esfuerzos, experiencias e investigaciones para propiciar la cooperación en esta materia. El mismo elaboró un documento publicado bajo el nombre de "Oportunidades de Colaboración en Investigación sobre Cambio Climático en los países de la Alianza del Pacífico"23. Donde se hace hincapié en "(...) los temas de mitigación para el desarrollo de sistemas productivos y extractivos bajos en emisiones y otros impactos ambientales; la adaptación a los cambios a través del desarrollo de índices e indicadores del impacto del cambio climático; y los efectos

23 El objetivo principal de ésta fue consolidar un acuerdo definitivo que sustituye al Protocolo de Kyoto, junto con los mecanismos propios sobre los fondos para mitigar el cambio climático así como los compromisos establecidos por cada signatario a fin de reducir las emisiones de gases de efecto invernadero. En este sentido, destacan el Programa de Reducción de Emisiones de Carbono causadas por la Deforestación y la Degradación de los Bosques; Planes Nacionales de Adaptación y; Fondo Verde para el Clima. 
del cambio climático sobre todo en regímenes de precipitación y eventos extremos", como parte de los trabajos previos a la COP20 (27 de noviembre de 2014).

En mayo de 2015 se dio inicio al proyecto "Cooperación Científica en Materia de Cambio Climático en la Alianza del Pacífico: Monitoreo de la Biodiversidad de nueva generación para apoyar procesos de adaptación y mitigación al cambio climático", a través de la Red Científica en materia de Cambio Climático (RICCC), en búsqueda del fortalecimiento de la cooperación entre los miembros con el objetivo de concebir una red interoperable de monitoreo regional de la biodiversidad en el entorno del cambio climático y que integre los respectivos sistemas nacionales. Este se materializó en el Grupo Técnico de Cooperación (GTC) de la AP. Sin embargo, hacia marzo de 2016 se produjo un hecho por demás destacable y sobre todo, esperable: Hacia una Plataforma de Crecimiento Verde de la AP, en donde, a partir de la Declaración de los Ministros del Ambiente de los cuatro países signaron un compromiso para la conformación de un espacio de diálogo, compuesto por siete puntos principales. Entre éstos, destacan la denominada estrategia verde que se haga eco del desarrollo sostenible teniendo en cuenta las particularidades de cada país, el fortalecimiento de las capacidades institucionales y políticas efectivas así como la necesaria articulación con el sector privado. Todo esto a fin de desarrollar una agenda que dé impulso a la sostenibilidad. De acuerdo a los intereses propios de esta investigación, resalta el punto 5 de la Declaración, ya que expresa "nuestra voluntad de articular y promover una agenda ambiental común, que aborde las prioridades ambientales compartidas y que contribuya con la implementación de los Objetivos de Desarrollo Sostenible (ODS) en el marco de la agenda 2030 de las Naciones Unidas" (Declaración de los Ministros del Ambiente de la Alianza del Pacífico, 2016). Y tal como lo señaló el Ministro del Ambiente de Perú, esta Plataforma permitirá incorporar la variable ambiental en la AP (Ministerio del Ambiente, Perú, 31 de marzo de 2016)

Por lo menos al nivel de cumbres da la sensación de que desea profundizarse en lo medioambiental, como se recoge de las mencionadas declaraciones conjuntas en el marco de las Conferencias sobre Cambio Climático (COP20 y COP21) y la Declaración de los Ministros de Ambiente (2016). Así, por ejemplo, los presidentes han instado a los países desarrollados a capitalizar el Fondo Verde para 
el Clima. Lo que es indudable es que destaca el procedimiento de diplomacia de cumbres, por cuanto no sólo no abunda la información oficial, así como tampoco el debate académico sobre los aspectos que aquí nos ocupan sino que por el contrario, la recolección de datos arroja sobre todo declaraciones presidenciales. Entre otros aspectos, La AP no ha propuesto, hasta la fecha, estudios sobre el uso de instrumentos económicos para la protección ambiental. Ya en 2015 se expresaron críticas respecto de que la AP, encarnada en los países que la componen, omitió el tema ambiental en la Cumbre de Paracas $(2015)^{24}$

Sin embargo, preliminarmente puede concluirse que las agendas se han enfocado sin dudas en los intercambios comerciales, dejando claramente de lado lo relativo a políticas medioambientales y por supuesto, un tema mucho más álgido para los miembros de la Alianza, como lo es la conflictividad alrededor de las actividades mineras ${ }^{25}$ y/o el narcotráfico. Como pudo observarse, es poca la producción, tanto en términos de lo que ha adelantado la Alianza respecto del medio ambiente como de los debates académicos que ésta debería haber suscitado al respecto. Con esto por delante, se procederá entonces al análisis de las agendas ambientales de los Estados que forman parte de esta arquitectura subregional.

\section{Las agendas nacionales de los países que componen la Alianza del Pacífico en perspectiva}

Esta sección se focaliza en el análisis de contenido de las agendas ambientales nacionales de México, Chile, Perú y Colombia que, sobre la base de las respectivas constituciones nacionales más las leyes que de ellas emanan específicamente sobre cambio climático, biodiversidad y desarrollo sostenible, permitirán establecer convergencias, divergencias y/o compatibilidades frente a los desafíos que

24 Los jefes de Estado se manifestaron en avanzar en un área de integración profunda sobre los cuatro pilares de trabajo del arreglo: libre movilidad de bienes, servicios, capitales y personas bajo el eje de la cooperación. Texto completo: https://alianzapacifico. net/wp-content/uploads/2015/07/DECLARACION-LAM-BID.pdf

25 Debe darse cuenta de que Alianza del Pacífico posee un Grupo de Trabajo denominado Grupo de Desarrollo Minero, Responsabilidad Social y Sustentabilidad de la Alianza del Pacífico (GTDM) que hace explícita mención al aprovechamiento sustentable de los recursos mineros pero en la recolección de la información no ha sido posible más que recabar su objetivo y misión, lo que lógicamente no deriva a la idea arriba expresada. 
supone la construcción de una agenda ambiental en la Alianza del Pacífico. Para esto, se han construido dos tablas (ver anexos) que a su vez consideran dos niveles de análisis: 1- Nivel Normativa ambiental: Constitución, Leyes Generales e Instituciones ambientales en los Estados miembro de la AP y; 2- Nivel Programas y Estrategias de Acción en materia ambiental de los Estados miembro de la AP. Esto, por cuanto permiten una mejor visualización respecto del análisis de convergencias, divergencias y/o compatibilidades entre las medidas de los cuatro países a fin de identificar a partir de ellas cuáles son las áreas de convergencia desde las cuales se puede plantear la cooperación o al revés.

\section{Nivel Normativa ambiental: Constitución, Leyes Genera- les e Instituciones ambientales en los países miembros de la Alianza del Pacífico}

En la Tabla I (ver anexo), es decir, partiendo desde más alto nivel normativo, puede apreciarse que en todos los países el tema ambiental posee rango constitucional. Si bien, todas las constituciones datan de los años 90, donde el medio ambiente se encuentra contemplado en capítulos y artículos específicos, destaca el hecho de que su primera inclusión en América Latina se dio a partir del artículo 27 de la Constitución Política de los Estados Unidos Mexicanos en el año 1917. En 1999, los artículos 4 y 25 de esta Constitución fueron ajustados para incluir el "derecho a un ambiente adecuado para su desarrollo y bienestar" y el concepto de "sustentabilidad" (Brañes, 2001). El marco legal que deriva de la misma se establece sobre la base de dos leyes fundamentales: la Ley General del Equilibrio Ecológico y la Protección al Ambiente (1988) donde el Estado se compromete a "la preservación y restauración del equilibrio ecológico, así como al ambiente, en el territorio nacional y las zonas sobre las que la nación ejerce su soberanía y jurisdicción" (Artículo 1), entre otros y; la Ley General de Cambio Climático (Decreto $N^{\circ}$ 181de 2013), que tal y como reza su primer artículo, "establece disposiciones para enfrentar los efectos adversos del cambio climático". Sus enfoques principales son la regulación de las emisiones de los gases de efecto invernadero, la mitigación y adaptación al cambio climático (ecosistemas y personas), la educación e innovación así como la "transición hacia una economía competitiva, sustentable, y de bajas emisiones de carbono". (Diario Oficial de la Federación, México. 6 de junio de 2012). 
Esta última conlleva a la creación del Instituto Nacional de Ecología y Cambio Climático (INECC) y define la creación de un Sistema Nacional de Cambio Climático que se encargue de coordinar la política nacional de medioambiente y asegurar -entre otras atribuciones- la congruencia entre la definición y aplicación de los programas. Este Sistema se conforma por una Comisión Intersecretarial de Cambio Climático, un Consejo de Cambio Climático y el INECC, entre otros miembros. (Diario Oficial de la Federación, México. 6 de junio de 2012) También la Ley General del Equilibrio Ecológico y la Protección del Ambiente (1988) se ocupan de la biodiversidad, de las áreas naturales protegidas, define el desarrollo sustentable y deriva en la Estrategia Nacional sobre Biodiversidad (Diario Oficial de la Federación, México. 28 de enero de 1988), que será tratada más adelante.

Por su parte en Chile, la Constitución Política (texto refundido, coordinado y sistematizado en 2005), expresa el "derecho a vivir en un medio ambiente libre de contaminación" y que "Es deber del Estado velar para que este derecho no sea afectado y tutelar la preservación de la naturaleza". (Capítulo III "De los deberes y derechos constitucionales", art. 8) La Ley N 19.300 sobre Bases Generales del Medio Ambiente (1994) contempla en su conjunto las cuestiones que aquí interesan -cambio climático, biodiversidad y desarrollo sustentable- así como también las herramientas de la gestión ambiental, la definición de responsabilidad en caso de daño ambiental, y la creación tanto del Ministerio del Medio Ambiente como de un Fondo de Protección Ambiental ${ }^{26}$. También, especifica la creación de la Superintendencia del Medio Ambiente cuyas atribuciones son el control e inspección del cumplimiento con los requisitos de la propia ley -y de la cual hace parte-, la fiscalización ambiental y la atribución de sanciones. (Ministerio del Ambiente, 2011).

En Perú, la Constitución de 1993 especifica en el Titulo III Capitulo 2 "Del Ambiente y los Recursos Naturales" el buen uso de los recursos naturales, la Política Nacional Ambiental y la protección de la biodiversidad. (Ministerio de Energia y Minas, s/f). A diferencia de los casos previos, de aquí se deriva todo un entramado más amplio y complejo de normativas que propenden a la regulación de las varia-

26 Tiene como objetivo "financiar total o parcialmente proyectos o actividades orientados a la protección o reparación del medio ambiente, el desarrollo sustentable, la preservación de la naturaleza o la conservación del patrimonio ambiental”. 
bles ambientales. En primer lugar, en el Código del Medio Ambiente y los Recursos Naturales (1990), se distinguen definiciones y objetivos de la política ambiental, su planificación, la protección del medio ambiente, la biodiversidad, la importancia de la participación de la sociedad civil en esta materia y la protección de áreas naturales. (Código del Medio Ambiente y los Recursos Naturales, 1990). En segundo término, la Ley Orgánica № 26.821 para el Aprovechamiento Sostenible de los Recursos Naturales (1997) apunta al desarrollo sostenible "estableciendo un marco adecuado para el fomento a la inversión, procurando un equilibrio dinámico entre el crecimiento económico, la conservación de los recursos naturales y del ambiente y el desarrollo integral de la persona humana." (Ministerio de Medio Ambiente, s/f)

Por otra parte, la Ley № 27.446 del Sistema Nacional de Evaluación de Impacto Ambiental de 2001, preveía en la creación del Sistema Nacional de Evaluación del Impacto Ambiental (SEIA), "como un sistema único y coordinado de identificación, prevención, supervisión, control y corrección anticipada de los impactos ambientales", por lo que también describe los requerimientos para obtener la certificación ambiental (Ministerio del Ambiente, 2001). El SEIA está supervisado por el Consejo Nacional de Ambiente (CONAM). La Ley General del Ambiente (2004) establece los marcos relativos a la gestión ambiental y contrarrestar los causantes del cambio climático, la que se complementa con la Ley Marco del Sistema Nacional de Gestión Ambiental (2004) donde se delinean las estrategias nacionales para cumplir con los compromisos acordados en la Convención Marco de las Naciones Unidas sobre el Cambio Climático. Cierra el círculo la Política Nacional del Ambiente (2009), herramienta de planificación sectorial, regional y local por excelencia, que junto con el Acuerdo Nacional (2002) definen las orientaciones para el desarrollo sostenible con referencia al cambio climático.

Finalmente, Colombia es tan destacable en materia ambiental desde su constitucionalidad al punto que la Constitución Política de 1991 ha sido llamada "la Constitución Verde" (Brañes, 2001). De especial importancia son los artículos 79 y 80, por cuanto el primero especifica tanto que "Todas las personas tienen el derecho a gozar de un ambiente sano" y que "(...) Es deber del Estado proteger la diversidad e integridad del ambiente, conservar las áreas de especial importancia ecológica y fomentar la educación para el logro de estos fines." A la par que el segundo reza: "El Estado planificará el manejo 
y aprovechamiento de los recursos naturales, para garantizar su desarrollo sostenible, su conservación, restauración o sustitución. Además, deberá prevenir y controlar los factores de deterioro ambiental, imponer las sanciones legales y exigir la reparación de los daños causados. Así mismo, cooperará con otras naciones en la protección de los ecosistemas situados en las zonas fronterizas". (Artículo 80, Constitución Política de Colombia). Todo esto, sin descuidar que en sendos capítulos se tratan temáticas ambientales que se relacionan con la riqueza cultural y natural de la nación así como su protección (artículos 8 y 95), la atención de la salud y saneamiento ambiental (artículo 49), la función ecológica de la propiedad privada (artículo 58) y los bienes de uso público (artículo 63).

A partir de aquí se desprenden una serie de acciones encaminadas a brindar no sólo la regulación necesaria en estos aspectos sino también de dotar al Estado de la necesaria institucionalidad que planee, ejecute, administre, coordine y fiscalice las cuestiones relacionadas con el medio ambiente a través de planes, estrategias y acciones. Pero a la vez precursor resalta el Código Nacional de Recursos Naturales Renovables y de Protección del Medio Ambiente, uno de los primeros en la región (1974), que entiende que la preservación y el manejo de los recursos naturales siempre son de interés social. (Diario oficial N.34.243. 27/01/1975) Amplia y variada normativa ambiental ${ }^{27}$, entre la que destacan las que aprueban las distintas convenciones, convenios, acuerdos, protocolos y demás arreglos internacionales de los que participa el país, la Ley General del Ambiente (99 de 1993) que crea el Ministerio del Ambiente y organiza el Sistema Nacional Ambiental (SINA) (Diario Oficial No. 41.146, de 22 de diciembre de 1993), aquella que expide el Código de Minas (685 de 2001), el Decreto 1200 de 2004 "Por el cual se determinan los Instrumentos de Planificación Ambiental" o el más reciente y novedoso del Ministerio del Ambiente y Desarrollo Sostenible "Por el cual se establecen las condiciones para el montaje, instalación y puesta en funcionamiento de zonas del territorio nacional para la ubicación temporal de miembros de las organizaciones armadas al margen de la ley en el marco de un proceso de paz" (Decreto 1397 de 2016).

27 Para mayor detalle, se recomienda visitar: http://www.minambiente.gov.co/index.php/ normativa/leyes 


\section{Nivel: Programas y Estrategias de Acción en materia am- biental de los Estados miembro de la Alianza del Pacífico}

Como se desprende de lo constatado en el apartado 4.1., puede aseverarse que todos los marcos normativos nacionales y las instituciones creadas a estos respectos se enfocan en el cambio climático, la biodiversidad, el desarrollo sostenible y las intrínsecas relaciones entre ellos, las que se deben ver plasmadas en estrategias, planes y programas. Son estos últimos aspectos los que constituyen el punto neurálgico de la presente, ya es en este nivel donde mejor se puede observar que existan divergencias, convergencias y/o compatibilidades en materia ambiental. Siguiendo la secuencia lógica previa, México, a partir de la Ley de Cambio Climático ha derivado el Programa Especial de Cambio Climático (PECC) y en concordancia, la estrategia Nacional de Cambio Climático Visión 10-20-40, la que se constituye en la herramienta per se diseñada para combatir el cambio climático con el horizonte de los próximos diez, veinte y cuarenta años. Según la misma, el PECC es el "instrumento rector de la política nacional en el mediano y largo plazo para enfrentar los efectos del cambio climático y transitar hacía una economía competitiva, sustentable, y de bajas emisiones de carbono", además de que define los planes sexenales a este respecto. (Secretaria de Medio Ambiente y Recursos Naturales, 2013) ${ }^{28}$. También, México establece un Inventario Nacional de Gases de Efecto Invernadero conforme a su adhesión a la Convención Marco de las Naciones Unidas sobre el Cambio Climático (CMNUCC), con el fin de medir la emisión de aquellos gases que no son contemplados por la Conferencia de Montreal. (Secretaria de Medio Ambiente y Recursos Naturales, 2013). Paralelamente, complementa en esta línea la Estrategia Nacional sobre Biodiversidad (2000) que abarca todos los objetivos y acciones que se buscan implementar a cincuenta años en términos de preservación de la biodiversidad y desde 2002 se desagrega en Estrategias Estatales sobre Biodiversidad (Comisión Nacional para el Conocimiento y Uso de la Biodiversidad, s.f.).

28 Resulta interesante resaltar que esta estrategia cuenta con tres temas principales. Como primer eje aparecen los seis pilares de la política nacional de cambio climático que van desde las políticas fiscales a la definición de instrumentos de medición y evaluación. El segundo, refiere a la adaptación a los efectos del cambio climático enfocado en el sector social, la infraestructura energética y el uso y conservación "sustentables" de los ecosistemas. El ultimo eje hace énfasis en el desarrollo bajo en emisiones/mitigación con un enfoque en la transición energética y los Contaminantes Climáticos de Vida Corta entre otros. (Secretaria de Medio Ambiente y Recursos Naturales, 2013) 
Como ejemplo dable a destacar que ilustra lo aquí expuesto, en un evento paralelo a la COP 21, el gobierno mexicano trató la relevancia de la relación entre cambio climático y biodiversidad, haciendo hincapié en la creación de infraestructura resiliente y sobre aquella considerada estratégica, como el sector energético. Dado lo proclive del país a las catástrofes naturales, se busca una tasa de deforestación cero para el año 2030, la reducción de la vulnerabilidad en sitios específicos y sistemas de alerta temprana. Además, México forma parte de la Coalición por un Alto Nivel de Ambición (High Ambition Coalition), que buscaba que el nuevo acuerdo de París incluya una meta de $1.5^{\circ} \mathrm{C}$, y no de $2^{\circ} \mathrm{C}$ como fue acordado previamente a nivel internacional (Mendívil, 2015)

Desde la particularidad chilena, la Estrategia Nacional Chilena de Cambio Climático se desarrolla a través del Plan de Acción Nacional de Cambio Climático (PANCC), siendo su herramienta principal el Plan Nacional de Adaptación al Cambio Climático (PNACC), entendido en tanto "instrumento articulador de la política pública chilena de adaptación al cambio climático" (Ministerio del Medio Ambiente, 2015) y sus respectivos Planes Sectoriales (Departamento de Cambio Climático del Ministerio del Medio Ambiente, 2015) De acuerdo con esta fuente que forma parte de la cartera ambiental, Chile reconoce su vulnerabilidad ante el cambio climático, de manera que el PANCC 2008-2012 se basa en tres ejes fundamentales: "adaptación a los impactos del cambio climático", "mitigación de las emisiones de los gases de efecto invernadero", y "creación y fomento de capacidades en cambio climático".

En concordancia con su adhesión a la Convención Marco de Naciones Unidas sobre Cambio Climático, el país no sólo cuenta con un Sistema Nacional de Inventarios de Gases de Efecto Invernadero, sino que adicionalmente, en 2007 se comprometió voluntariamente a reducir sus emisiones por este concepto en un 20\% en el período comprendido entre 2007 y 2020 (Ministerio del Medio Ambiente, s.f.) Luego implementó un impuesto a las emisiones de Co2 en virtud del cual se imponen, a partir de 2017, u\$s 5 (cinco dólares estadounidenses) por cada tonelada de CO2 emitido por establecimiento. (Ley 20.780 de 2014) Como complemento, la Estrategia Nacional para la Conservación y Uso Sustentable de la Biodiversidad (2003) tiene como objetivo general conservar la biodiversidad del país, promoviendo su gestión sustentable; valga como ilustración que en 2015 
publicó la Política Forestal 2015-2035, que apunta a un "desarrollo forestal sustentable". Acompaña a estas iniciativas la implementación de la Agenda Energética para Chile 2014-2018, que da la prioridad al uso de energías limpias, de forma que "con esta agenda, un 45\% de la capacidad de generación eléctrica que instalaremos entre 2014 y 2025 provendrá de energías renovables no convencionales" (Gobierno de Chile, 2015)

Por su parte, Perú cuenta con una Estrategia Nacional ante el Cambio Climático, siendo su misión central la reducción de los riesgos e impactos previsibles a la vez que reconoce "(...) el potencial nacional para la captura, la conservación de reservas de carbono, y la mejor gestión de las emisiones de los GEl, lo que permitirá sentar las bases para una economía baja en carbono."(Ministerio del Ambiente, 2015). Entre sus objetivos es taxativa en señalar que "la población, los agentes económicos, y el Estado incrementen conciencia y capacidad adaptativa frente a los efectos adversos y oportunidades del cambio climático" (Ministerio del Ambiente, 2015) En relación a la misma, se identifican el Plan de Acción de Adaptación y Mitigación frente al Cambio Climático (2010), las estrategias Regionales de Cambio Climático sobre la base de la Ley Orgánica de Gobiernos Regionales - a fin de que cada región contemple sus propias especificidades- y el Plan de Gestión de Riesgos y Adaptación al Cambio Climático en el Sector Agrario para el período 2012-2021. (Ministerio del Ambiente, 2015). Completa el abordaje de estos aspectos el Plan Bicentenario El Perú hacia el 2021 que sitúa en su eje número 6 "Recursos naturales y medio ambiente" el diseño de políticas acordes a la adaptación a esta problemática. Por último, el país desarrolla su propio Inventario de Gases de Efecto Invernadero (INFOCARBONO) en el contexto de su adhesión a la Convención Marco de las Naciones Unidas sobre el Cambio Climático.

Respecto de la biodiversidad, el Estado peruano cuenta con la Estrategia Nacional de Diversidad Biológica al 2021 que, articulada sobre la base de cinco objetivos principales que contemplan la conservación y el uso sostenible de la biodiversidad mediante la participación de todos los actores sociales, entiende que "Al 2021 el Perú conserva y usa racionalmente su megabiodiversidad revalorando los conocimientos tradicionales asociados para la satisfacción de las necesidades básicas y de bienestar de las actuales y futuras generaciones en el marco de un desarrollo sostenible inclusivo y competitivo". 
(Ministerio del Ambiente, 2014). A modo de corolario, el Plan Nacional de Acción Ambiental 2011-2021 se dedica a la planificación a largo de las políticas ambientales que destacan con mayor urgencia, como lo es el caso de la deforestación y los gases de efecto invernadero. (Ministerio del Ambiente, 2015)

Por último, como caso de estudio que completa este análisis, Colombia ubica su agenda ambiental dentro del Plan de DesarroIlo 2014-2018, más específicamente en su Capítulo X denominado Crecimiento Verde, por cuanto la visión del Estado, planteada por el Departamento Nacional de Planeación (2015) puede resumirse en la consecución de tres objetivos principales. El primero, "avanzar hacia un crecimiento sostenible y bajo en carbono", pone la lupa sobre aquellas variables que permiten el logro del mismo, tales como energías renovables, eficiencia energética, ecoinnovación, gestión de la energía en sectores mineros y de hidrocarburos, entre otros. En segundo término, se busca "proteger y asegurar el uso sostenible del capital natural y mejorar la calidad y gobernanza ambiental" lo cual refiere a la preservación de la biodiversidad, disminución de deforestación, producción y consumo sustentables, programas de fomento de los negocios verdes, gestión de contaminación del aire y del suelo. Para esto la Política Nacional de Biodiversidad se desarrolla sobre los tres ejes "Conservar, Conocer y Utilizar"29.

Pero lo que es más importante: trata del diseño de una política nacional de cambio climático, compuesta por el Plan Nacional de Adaptación al Cambio Climático como eje, del que se desprenden la Estrategia Colombiana de Desarrollo Bajo en Carbono y la Estrategia Nacional de Reducción de Emisiones por Deforestación y Degradación Forestal (REDD+). El Plan Nacional de Adaptación al Cambio Climático tiene como finalidad la reducción del "(...) riesgo y los impactos socio-económicos y ecosistemicos asociados a la variabilidad y al cambio climático en Colombia" y se compone de cuatro objetivos específicos, a saber: "1- Generar un mayor conocimiento sobre los riesgos potenciales e impactos actuales, dentro de lo que se incluye su valoración económica; 2- Aprovechar las oportunidades asociadas al cambio y a la variabilidad climática; 3- Incorporar la gestión del

29 El primero alude al Sistema Nacional de Áreas Naturales Protegidas, el segundo a desarrollar y comunicar el conocimiento mientras que el tercero se enfoca en el fomento de la sustentabilidad. 
riesgo climático en la planificación del desarrollo sectorial y territorial y; 4- Identificar, priorizar, implementar, evaluar y hacer seguimiento de medidas de adaptación para disminuir la vulnerabilidad y exposición de los sistemas socio-económicos ante eventos climáticos". (Departamento Nacional de Planeación, 2012). Por último, se busca "lograr un crecimiento resiliente y reducir la vulnerabilidad frente a los riesgos de desastres y al cambio climático". (Departamento Nacional de Planeación, 2015)

En concordancia con esto, la Estrategia Colombiana de Desarrollo Bajo en Carbono (ECDBC) es un programa que "busca desligar el crecimiento de las emisiones de GEl del crecimiento nacional a través de medidas sectoriales de mitigación que contribuyen al desarrollo económico y competitividad de los sectores", que si bien, se compone por cinco objetivos principales, conviene resultar que entre éstos pretende formular alternativas sectoriales a partir de la variable de desarrollo bajo en carbono, regionalizar esta estrategia y promover el cambio climático en las instituciones como un tema transversal de desarrollo. (Ministerio del Ambiente y Desarrollo Sostenible, s/f) Todo este complejo entramado no estaría completo sin destacar la Calculadora del Carbono 2050 en tanto herramienta de "(...) planeación y toma de decisiones que proyecta diferentes escenarios de reducción de las emisiones de gases de efecto invernadero (...) teniendo en cuenta los diferentes sectores de la economía" (Ministerio de Ambiente y Desarrollo Sostenible, 2016). Por último, Colombia posee un Inventario Nacional de Gases de Efecto Invernadero acorde al Convenio Marco de las Naciones Unidas sobre el Cambio Climático.

De manera que a partir de este análisis se destacan las convergencias, ya que todas las agendas establecen disposiciones para enfrentar los efectos adversos del cambio climático, contemplan la conservación y el uso sostenible de la biodiversidad mediante la participación de todos los actores sociales y se encara el desarrollo sostenible sobre la base de la colaboración de instituciones públicas y privadas para desarrollar la investigación sobre estos temas y proveer asistencia técnica y científica en la formulación y evaluación de las políticas nacionales ambientales respectivas. Sus enfoques principales son la regulación de las emisiones de los gases de efecto invernadero, la mitigación y adaptación al cambio climático (ecosistemas y personas), la educación e innovación así como la transición hacia una economía competitiva, sustentable, y de bajas emisiones de carbono. 
Todos los Estados bajo estudio cuentan con instrumentos rectores de política para en el mediano y largo plazo enfrentar los efectos del cambio climático así como de inventarios nacionales de gases de efecto invernadero, conforme a su adhesión a la Convención Marco de Naciones Unidas sobre el Cambio Climático y en algunos casos, con el fin de medir aquellos gases que no son contemplados por la Conferencia de Montreal.

Colofón: debe recalcarse que no existen divergencias sino que predominan ampliamente las convergencias y concordancias entre las respectivas agendas nacionales; en todas se enfatiza la relación entre cambio climático, biodiversidad y desarrollo sostenible, haciendo especial hincapié en la creación de infraestructura resiliente y sobre todo aquella estratégica, como el sector energético. Todo esto, con el fin de proteger y asegurar el uso sostenible del capital natural y mejorar la calidad y gobernanza ambiental y como resalta por sí sólo, perfectamente se adecuan a la iniciativa planteada para una Plataforma de Crecimiento Verde de la AP.

\section{Aportes conclusivos}

Todo lo hasta aquí expresado conduce necesariamente a la idea de que las respuestas a los problemas que plantean los temas ambientales -entendidas éstas como políticas e instituciones- sólo pueden ser resueltos bajo la óptica del regionalismo. Sin embargo, el primer problema se presenta en torno de las diversas estrategias regionales así como de la dicotomía representada como Atlántico-Pacífico o, al decir de Zapata (2014, p. 64) "(...) Latinoamérica al 'norte' de Panamá - Latinoamérica al 'sur' de Panamá". Esto puede producir una superposición de estilos o estrategias de integración que, al combinar distintos modelos de desarrollo económico, político y social, podrían indefectiblemente estarnos conduciendo más hacia la fragmentación que a la integración.

Lo que debe resolver el nuevo de tipo de relacionamientos regionales que se plantean en nuestra región es que aún a diferencia de sus distintos tipos y apuestas, esto se trata de una cuestión ineludible. La no incorporación de la escala física -la relación entre la naturaleza, los recursos naturales, la degradación ambiental y el crecimiento económico- resulta, concordando con Falconí, (2014, 
p. 45) una grave omisión en la integración regional, con más razón cuando estos procesos auguran ambiciosos proyectos sobre todo energéticos y comerciales.

Respecto de la AP, en principio resulta menester cuestionar la escasez del estado del arte sobre el tratamiento de los temas ambientales en esta arquitectura. Se adolece de trabajos que analicen la temática específica en la AP, pero aquí resulta muy difícil dilucidar si esto se deba a su reciente conformación, por qué no capta la atención de la comunidad académica en este sentido o si por tratarse de un arreglo de tipo neoliberal no suscita el interés por el estudio de esta cuestión. Hasta ahora lo visto en tanto bloque se centra sólo en torno del cambio climático, relegando las otras dimensiones ambientales y lo que es más preocupante aún: persisten los silencios respectos de las actividades extractivas que caracterizan a las cuatro economías. La Declaración que impulsa la Plataforma de Crecimiento Verde (2016) es sin dudas un importante avance que podría augurar el comienzo del necesario abordaje integral de las múltiples dimensiones que involucra el problema. Pero esta última, no deja de ser más que siete puntos objetivo que en nada se condicen con un documento exhaustivo que permita extraer conclusiones un poco más contundentes, sino que podría considerarse sólo como un "disparador" para iniciar conversaciones al respecto. No obstante, no ha hecho ninguna mención acerca del espacio geográfico compartido, el océano Pacífico, aunque de materializarse las iniciativas propuestas esto podría ser implícitamente deducible del impacto de las mismas. Y como se ha observado a lo largo del presente, con estos objetivos por delante sus logros no tendrían por qué dificultarse con agendas ambientales nacionales convergentes y concordantes.

Por otra parte, una vez más puede corroborarse que las participaciones e intervenciones, que respecto de esta materia ha tenido el bloque en los foros internacionales han respondido al predominio de los gobiernos por sobre la apuesta a la institucionalidad. Esto no aleja a AP de las sombras de una larga tradición presidencialista en Latinoamérica que ha ido en detrimento de las instituciones y de las aspiraciones de supranacionalidad, que se han traducido en un freno a la integración regional.

Pero no todo puede ser un panorama poco auspicioso en este sentido. Se ha visto aquí que las agendas nacionales de los países 
miembro son por demás completas, existiendo convergencia, ya que apuntan al logro de los mismos objetivos, y adicionalmente son compatibles, por cuanto las consecuciones de las metas de un Estado no suponen un escollo para los demás miembros y por ende, pueden lograrse sin entrar en contracción. No sólo no se ven divergencias entre sí, ya que ninguno de los casos analizados entorpece los objetivos de los demás Estados, sino que adicionalmente se articulan con lo propuesto por parte del Comité Científico y por la Declaración de los Ministros del Ambiente de la AP (2016). Además, si la AP se ha centrado hasta ahora en el cambio climático, sólo con recoger y armonizar las por demás completas y exhaustivas legislaciones nacionales, puede comenzar a focalizarse de igual manera en biodiversidad y desarrollo sostenible.

Estas observaciones permiten especular con que los países que componen la AP podrían perfectamente explotar estas convergencias y compatibilidades entre sus agendas ambientales con el propósito de profundizar las políticas existentes y que para en un más largo plazo estas pudiesen convertirse en políticas e instituciones del bloque. Pueden, por ejemplo, coordinarse acciones para establecer estadísticas regionales que homologue la información biofísica, pasivos ambientales, datos confiables sobre flujos de materiales y energía, etc., que permitirían mejorar los procesos de toma de decisiones y la comprensión de las relaciones entre economía, personas y medio ambiente. Como se afirmó desde el principio, prevalecen en la región patrones de cooperación divergentes y un amplio abanico de organizaciones regionales que abordan diferentes temas y representación proyectos político-ideológicos diferentes; sin embargo, este panorama también abre "(...) innumerables avenidas para investigar la integración regional y su gobernanza (Quiliconi, 2014, p. 181). Si en el caso analizado los miembros muestran claras convergencias y concordancias para hacer posible una agenda ambiental completa propia de la AP, pueda este ser el inicio para dar un giro al regionalismo neoliberal, el por un lado no puede continuar haciendo caso omiso de los impactos ambientales de las actividades económicas y lo mismo, si los países que integran el arreglo han demostrado tal preocupación, cómo no hacerla parte de esta iniciativa común. 


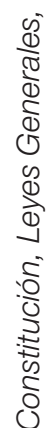

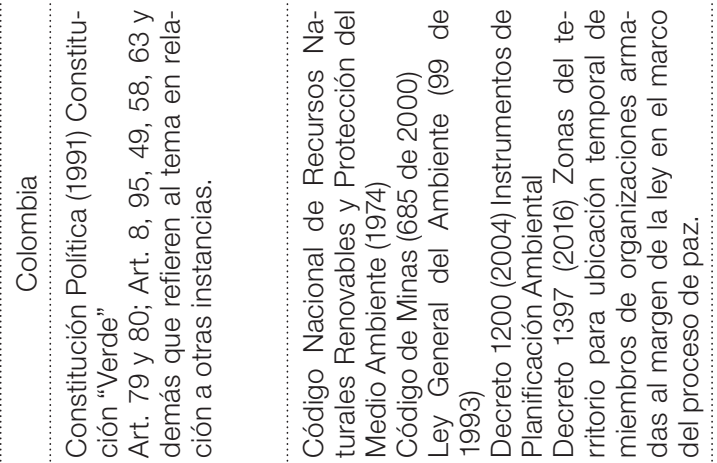

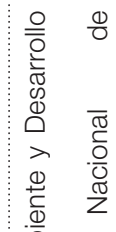

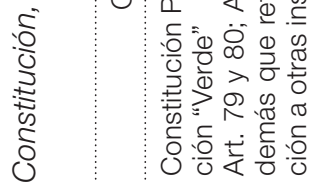

$\frac{\dot{d}}{d}$

$\stackrel{\partial}{\Sigma}$

๖े

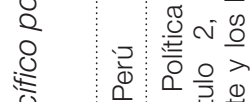

¿

$\frac{1}{\partial}$

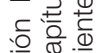

:응

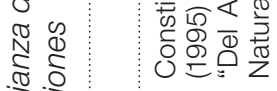

文

(大)

$\frac{0}{0} \stackrel{\infty}{5}$

है

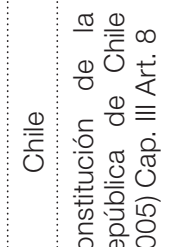

0
ग्र

(1)

平

$\begin{array}{ll}\infty & 0 \\ \infty & 0 \\ 0 & 0 \\ 0 & 0\end{array}$

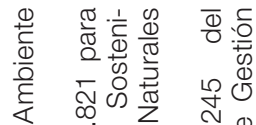

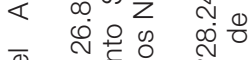

ब。

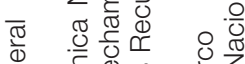

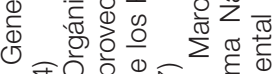

৩

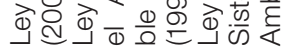

$\frac{\mathrm{Q}}{\mathrm{\varepsilon}}$

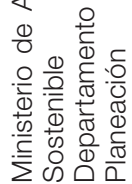

क 응

๑ $\Sigma$

ㅇํㅇ Ð

का

乙 $\frac{\sqrt{0}}{\mathrm{~d}} \cdot \frac{\mathrm{d}}{\mathrm{a}}$

वे ब

定

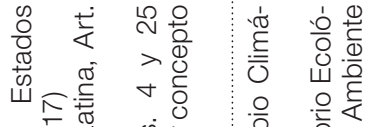

ฮ)

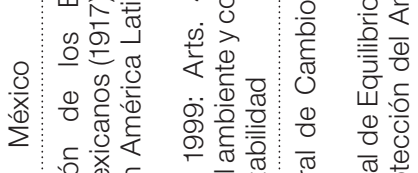

:

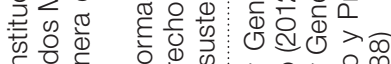

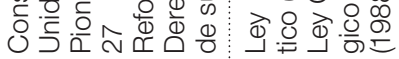

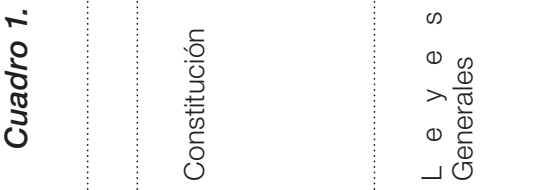

$\infty$
$0 \frac{\infty}{\frac{0}{d}}$
$0 \frac{\frac{1}{d}}{\square}$

$\frac{0}{\frac{1}{0}}$
$\frac{0}{0}$
$\frac{1}{\frac{1}{2}}$
$\frac{0}{0}$
$\frac{0}{0}$
$\frac{0}{0}$
$\frac{0}{2}$
$\frac{\pi}{0}$
.$\frac{0}{0}$
$\frac{0}{0}$
0

$\bar{\Phi}$

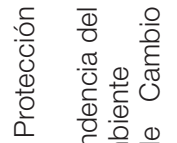

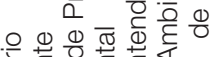

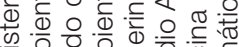

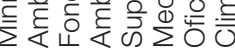

$>>\bar{\Phi} \frac{1}{0}$

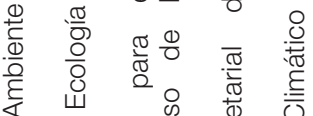

\& $\frac{1}{0}$ व

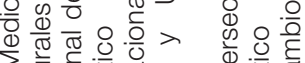

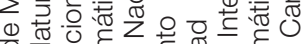

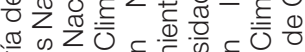

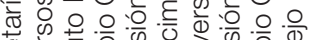
क

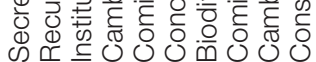

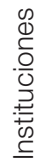




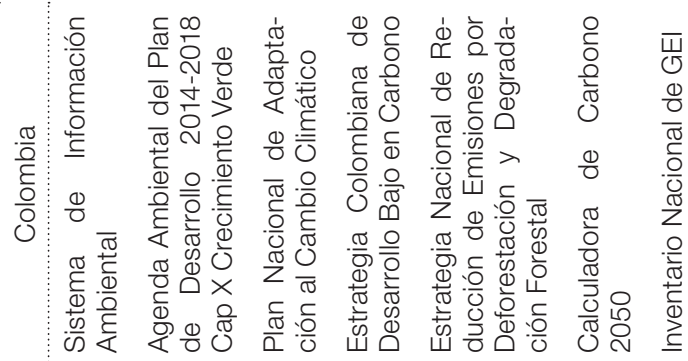

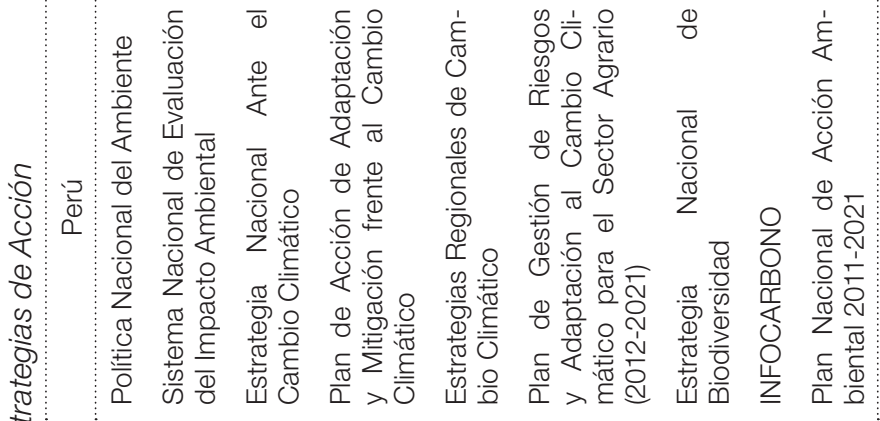

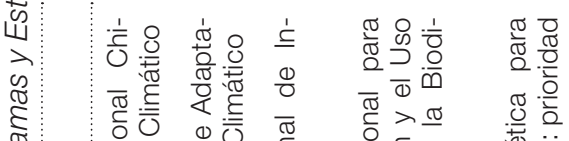

क)

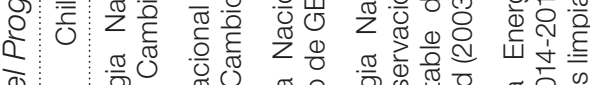

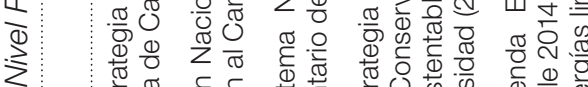

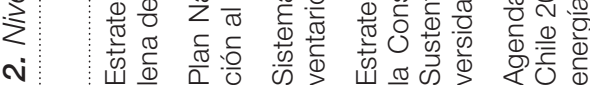

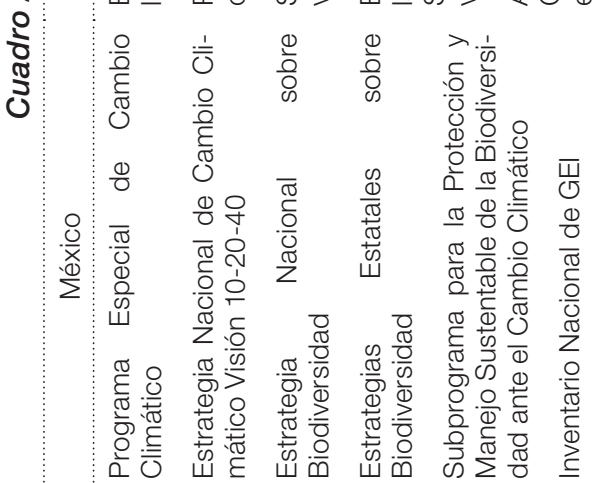

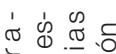

के

的界

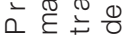




\section{Bibliografía}

Alianza del Pacífico (s/f) ¿Qué es? Recuperado de https://alianzapacifico. net/que-es-la-alianza/

Alianza del Pacífico (2014) Oportunidades de colaboración en Investigación sobre Cambio Climático en los países de la Alianza del Pacífico: Monitoreo de la Biodiversidad de nueva generación para apoyar procesos de adaptación y mitigación al Cambio Climático. Recuperado de https://alianzapacifico.net/cooperacion-cientifica-en-materia-de-cambio-climatico-en-la-alianza-del-pacifico-monitoreo-de-la-biodiversidad/

Alianza del Pacífico (2015) X Cumbre, Paracas, Perú. Recuperado de https://alianzapacifico.net/wp-content/uploads/2015/07/DECLARACION-LAM-BID.pdf

Alianza del Pacífico (2016) Declaración de los Ministros del Ambiente de la Alianza del Pacífico hacia una Plataforma de Crecimiento Verde. Recuperado de https://alianzapacifico.net/declaracion-de-los-ministros-de-ambiente-de-la-alianza-del-pacifico-hacia-una-plataforma-de-crecimiento-verde/

Ardila, M. (Ed.) (2012) El Pacífico latinoamericano y su inserción internacional. Bogotá: Siglo del Hombre Editores.

Bartesaghi, I. (2014) "América Latina y Asia Pacífico. Realidades que definen la agenda", Observatorio América Latina Asia Pacífico, ALADI-CAF-CEPAL, pp. 1-21. Recuperado de www.observatorioasiapacifico.org

Bergamaschine, J. Mata Diz y Ribeiro Volpini, S. (2011) El regionalismo y la integración en el Mercosur, Revista Ética e Filosofia Política - No 13 - Volume 2 - Junho. Recuperado de http://www.ufjf.br/eticaefilosofia/files/2011/05/13_2_diz.pdf

Bernal Meza, R. (2015) Alianza del Pacífico versus ALBA y MERCOSUR: Entre el desafío de la convergencia y el riesgo de la fragmentación de Sudamérica. Pesquisa \& Debate, SP, vol 26 N 1 (47), pp. 1-34, jan-mar. 
Bitar, S. (2014) Las tendencias mundiales y el futuro de América Latina, Santiago de Chile: CEPAL-Diálogo Interamericano, Serie de Gestión Pública 78.

Borón, Atilio (2013). Santos, la conjura contra Venezuela y la Alianza de Pacífico. Atilio Borón Blog. Julio. Recuperado de http://www.atilioboron.com.ar/2013/05/santos-la-conjura-contra-venezuela-y-la. html

Botello, Páez-Osuna et al (2014) Pacífico mexicano. Contaminación e impacto ambiental: diagnóstico y tendencias. UAC, UNAM-ICMYL, CIAD MAZATLÁN, CIBNOR, CICESE, $930 \mathrm{p}$.

Brañes, R. (2001). Informe sobre el desarrollo del derecho ambiental Latinoamericano: Su aplicación después de diez años de la Conferencia de las Naciones Unidas sobre el Medioambiente y el desarrollo. México, D.F.: Programa de las Naciones Unidas para el Medio Ambiente, Oficina Regional para América Latina y el Caribe.

Briceño Ruiz, José (2012) "La Alianza del Pacífico: la viabilidad de un naciente bloque regional”, en Ardila, Martha (ed.), Bogotá: Pontificia Universidad Javeriana, pp. 135-158.

Bustamante (2011) Comparación de políticas ambientales en la Unión Europea, Comunidad Andina y Mercosur Politeia, vol. 34, núm. 47, julio-diciembre, 2011, pp. 33-54 Universidad Central de Venezuela Caracas, Venezuela

Caldentey del Poz, P. Santos Carrillo, F. (2014) Las implicaciones para América Latina de la renovación de paradigmas sobre regionalismo e integración. Congreso REEDES. Recuperado de http://www.uhu. es/IICIED/pdf/7_9_regiona.pdf

Código Nacional de Recursos Naturales Renovables y Protección del Medio Ambiente (1974) República de Colombia. Recuperado de biblovirtual.minambiente.gov.co:3000/DOCS/MEMORIA/MADS.../ MADS-0026.pdf

Conferencia de Naciones Unidas sobre el Cambio Climático (1994) Recuperado de http://unfccc.int/resource/docs/convkp/convsp.pdf 
Conferencia de París sobre el Clima (2015) Acuerdo de París. Recuperado de http://newsroom.unfccc.int/es/acuerdo-de-paris/

Comisión Económica para América Latina y el Caribe (CEPAL) (2014) La Alianza del Pacífico y el MERCOSUR Hacia la convergencia en la diversidad

Constitución de la República de Chile (2005)

Constitución Política de Colombia (1991)

Constitución Política de los Estados Unidos Mexicanos (1917)

Constitución Política de Perú (1993)

Decreto 1397 (2016) Ministerio del Ambiente y Desarrollo Sostenible. República de Colombia. Recuperado de www.minambiente.gov. co/images/normativa/app/decretos/cd-decreto-1397.pdf

De Lisio, A. (2013) Desarrollo sustentable e integración regional, ILDIS, Caracas, Venezuela. Noviembre.

Decreto No 1200 (2004) Instrumentos de Planificación Ambiental. República de Colombia. Recuperado de http://www.ideam. gov.co/documents/51310/536020/Decreto+1200+de+2004. pdf/6c173c1d-7bc3-49bc-a6cf-04539795b482

Decreto No 1397 (2016) Por el cual se establecen las condiciones para el montaje, instalación y puesta en funcionamiento de zonas del territorio nacional para la ubicación temporal de miembros de organizaciones armadas al margen de la ley en el marco de un proceso de paz. Ministerio de Ambiente y Desarrollo Sostenible. Bogotá. Recuperado de http://www.minambiente.gov.co/images/normativa/app/decretos/cd-decreto-1397.pdf

Departamento de Cambio Climático del Ministerio del Medio Ambiente. Plan Nacional de Adaptación al Cambio Climático. Santiago de Chile. 
Departamento Nacional de Planeación. (2012). PNACC: Plan Nacional de Adaptación al Cambio Climático ABC: Adaptación Bases Conceptuales, Marco Conceptual y Lineamientos. Bogotá .

Departamento Nacional de Planeación. (2015). Plan Nacional de Desarrollo Todos por un nuevo país Tomos 1 y 2. Bogotá.

Diario Oficial de la Federación (2012) México, 6 de junio

Gobierno de Chile. (2015). Contribución Nacional Tentativa de Chile (INDC) para el Acuerdo Climático Paris 2015.

Gobierno de la República. (2013). ENCC 2013. Estrategia Nacional de Cambio Climático Visión 10-20-40. México, D.F.: Secretaria de Medio Ambiente y Recursos Naturales, Subsecretaria de Planeación y Política Ambiental, Dirección General de Políticas para el Cambio Climático.

Falconí, F. (2014) Decálogo de las decisiones esenciales: acciones ambientales que UNASUR podría proponer. LÍNEASUR Revista de Política Exterior del Ministerio de Relaciones Exteriores y Movilidad Humana Número 8, mayo/agosto (Vol. III, Issue 8, May-August, 2014) Quito, Ecuador, pp. 42-57.

Friedrich-Naumann-Stiftung für die Freiheit (2014) La ruta hacia la Alianza del Pacífico. Situación del comercio y el ambiente en los países miembro y en los países observadores candidatos a miembro. Recuperado de http://www.la.fnst.org/index.php/medio-ambiente/ item/252-la-ruta-hacia-la-alianza-del-pac\%C3\%ADfico

García, J. (2013) Alianza del Pacífico. ¿Hacia dónde vamos? Agenda Internacional Año XX, Nº 31, 2013, pp. 43-54

Gudynas, E. (2002) La Ecología Política de la Integración: reconstrucción de la ciudadanía y regionalismo autónomo. En Ecología Política. Naturaleza, sociedad y utopía. CLACSO, Buenos Aires. pp. 137-152. Recuperado de http://biblioteca.clacso.edu.ar/clacso/ gt/20100930023829/8moreira.pdf

Haas, E. (1971) The Study of Regional Integration: Reflections on the Joy and Anguish of Pretheorizing, en Lindberg, L. y Scheingold, S. 
(Eds.) Regional Integration: Theory and Research. Harvard University Press. Cambridge. pp. 3-44.

Krippendorf, K. (2004) Content Analysis: An Introduction to Its Methodology (2nd ed.). Thousand Oaks, CA: Sage.

Ley № 19.300 (1994) Bases Generales del Medio Ambiente. República de Chile. Recuperado de www.sinia.cl/1292/articles-51743_ Ley19300_12_2011.pdf

Ley N 685 (2001) Código de Minas. República de Colombia. Recuperado de www.minambiente.gov.co/images/normativa/leyes/2001/ ley_0685_2001.pdf

Ley General de Cambio Climático (2012) México. Recuperado de www. inecc.gob.mx/descargas/2012_lgcc.pdf

Ley General de Equilibrio Ecológico y la Protección del Ambiente (1988). México. Recuperado de http://www.salud.gob.mx/unidades/cdi/ nom/compi/l280188.html

Ley Nº 28611 (2004) Ley General del Ambiente. República de Perú. Recuperado de www.ana.gob.pe/sites/default/files/normatividad/ files/ley_n-28611.pdf

Ley General del Ambiente № 99 (1993) República de Colombia. Recuperado de www.oas.org/dsd/fida/laws/legislation/colombia/colombia_99-93.pdf

Ley Marco N 28.245 (2005) del Sistema Nacional de Gestión Ambiental. República de Perú. Recuperado de http://sinia.minam.gob.pe/normas/reglamento-ley-ndeg-28245-ley-marco-sistema-nacional-gestion-ambiental

Ley Orgánica 26821 (1997) para el Aprovechamiento Sostenible de los Recursos Naturales. República de Perú. Recuperado de www.ana. gob.pe/media/95192/ley_26821.pdf

Malamud, C. (2012): "La Alianza del Pacífico: un revulsivo para la integración regional en América Latina", ARI 46/2012, Real Instituto El Cano, 27 de junio. 
Mellado, Noemí (Coord. y Ed.) (2013). Problemáticas del regionalismo latinoamericano en los inicios del siglo XXI. San Salvador, El Salvador: Universidad Dr. José Matías Delgado.

Mendívil, A. (2015) El cambio climático y la biodiversidad para el desarrollo sustentable. Centro Mexicano de Derecho Ambiental. Recuperado de: http://www.cemda.org.mx/el-cambio-climatico-y-la-biodiversidad-para-el-desarrollo-sustentable/

Moreira, A. (2012a) Integración regional y medio ambiente. Reflexiones acerca de la dimensión ambiental del MERCOSUR, en Sociedad Latinoamericana para el Derecho Internacional. Conferencia Bienal: Río de Janeiro. Brasil. Recuperado de http://lasil-sladi.org/files/ live/sites/lasil-sladi/files/shared/Working\%20Papers/Working\%20 Paper\%207\%20Moreira.pdf

Moreira, A. (2012b) La protección ambiental en los procesos de integración. Aportes para cubrir un déficit del Mercosur. Anuario Mexicano de Derecho Internacional, México DF: Universidad Nacional Autónoma de México - Instituto de Investigaciones Jurídicas, pp. 211-232.

Naranjo Morales, A. (2013) El medio ambiente como eje de la integración: un trayecto inconcluso. Revista Ágora, Bogotá: Facultad de Relaciones Internacionales y Ciencia Política de la Universidad del Rosario.

Programa de Naciones Unidas para el Desarrollo (2015) Objetivos de Desarrollo Sostenible. Recuperado de http://www.undp.org/content/ undp/es/home/sustainable-development-goals.html

Quiliconi, C. (2014) Atlántico versus Pacífico: Las alternativas en competencia de la integración comercial en América Latina. Revista Relaciones Internacionales, Vol $29 \mathrm{~N}^{\circ}$ 47, Instituto de Relaciones Internacionales (IRI), Facultad de Ciencias Jurídicas y Sociales, Universidad Nacional de La Plata, La Plata, Argentina, pp. 165-184.

Quiliconi, C. (2015, febrero). Paper "Integración Latinoamericana: Regionalismo a la carta en un mundo multipolar.", International Studies Association, Nueva Orleans. 
Renner M. (2004), Environmental security: the policy agenda. Conflict, Security \& Development, 4 (3). 313-334.

Riggirozzi, P. (2010) "Crisis, Resilience and transformation: The Changing Architecture of Regionalism in Latin America" Paper presented at the annual meeting of the Theory vs. Policy? Connecting Scholars and Practitioners, New Orleans Hilton Riverside Hotel, The Loews New Orleans Hotel, New Orleans, LA Online.

Rodríguez Becerra, M. y Espinoza, G. (2002) Gestión ambiental en América Latina y el Caribe: evolución, tendencias y principales prácticas. Bogotá: Universidad de Los Andes. Libro complete disponible en http://www.manuelrodriguezbecerra.org/gestiona.htm

Saltalamacchia Z. (2014). The Mexican Agenda in Latin America: the Pacific Alliance, en Serbin, A. Anuario de la Integración Regional de América Latina y el Gran Caribe Nº10 2014, pp. 421-436.

Sanahuja, J. (2008) "¿Un mundo unipolar, multipolar o apolar? El poder estructural y las transformaciones de la sociedad internacional contemporánea", en VV AA, Cursos de Derecho Internacional de Vitoria-Gasteiz, Bilbao: Servicio Editorial de la Universidad del País Vasco, pp. 297-384

Sanahuja, J. (2010) La Unión Europea y el regionalismo latinoamericano: un balance. Investigación \& desarrollo vol. 21 (1), pp. 156-184.

Sanahuja, J. (2012) Regionalismo postliberal y multilateralismo en Sudamérica: el caso de UNASUR, en Serbin, A. Martínez, L. y Ramanzini Júnior, $\mathrm{H}$. Anuario de la Integración Regional de América Latina y el Gran Caribe Nº 9 pp. 19-72.

Serbin, A., Martín, L. y Ramanzini Júnior, H. (2014) ¿Atlántico vs. Pacífico?: América Latina y el Caribe, los cambios regionales y los desafíos globales Anuario de la Integración Regional de América Latina y el Caribe, No. 10.

Sociedad Nacional de Minería, Petróleo y Energía de Perú (2015) Perú, país minero. Recuperado de www.snmpe.org.pe/ 
Stuhldreher, A. (2013) "La dimensión medioambiental del MERCOSUR desde el enfoque del constructivismo: ¿Chances para $\mathrm{u} \mathrm{n}$ a construcción participativa?", en Mellado, N. (Coord y Ed.) Problemáticas del regionalismo latinoamericano en los inicios del siglo XXI. San Salvador, El Salvador: Universidad Dr. José Matías Delgado, pp. 249-267.

Vega, M. (2013) El medioambiente como un problema de seguridad en el regionalismo, en Mellado, N. (Coord. y Ed.) Problemáticas del regionalismo latinoamericano en los inicios del siglo XXI. San Salvador, El Salvador: Universidad Dr. José Matías Delgado, pp. 231-248.

Von Molkte, K. y Ryan, D. (2001) Medio ambiente y comercio: El caso de Mercosur y los principios de Winnipeg. Recuperado de https:// publications.iadb.org/handle/11319/2975 
